\title{
Parental Educational Attainment and Relatives' Substance Use of American Youth: Hispanics' Diminished Returns
}

\author{
Shervin Assari ${ }^{*}$, Cleopatra H. Caldwell², Mohsen Bazargan ${ }^{1}$ \\ ${ }^{1}$ Department of Family Medicine, Charles R. Drew University of Medicine and Science, Los Angeles, CA, USA \\ ${ }^{2}$ School of Public Health, University of Michigan, Ann Arbor, MI, USA \\ Email: *assari@umich.edu
}

How to cite this paper: Assari, S., Caldwell, C.H. and Bazargan, M. (2020) Parental Educational Attainment and Relatives' Substance Use of American Youth: Hispanics' Diminished Returns. Journal of Biosciences and Medicines, 8, 122-134.

https://doi.org/10.4236/jbm.2020.82010

Received: December 1, 2019

Accepted: February 25, 2020

Published: February 28, 2020

Copyright $\odot 2020$ by author(s) and Scientific Research Publishing Inc. This work is licensed under the Creative Commons Attribution International License (CC BY 4.0).

http://creativecommons.org/licenses/by/4.0/

\begin{abstract}
Background: Research on Marginalization-related Diminished Returns (MDRs) has shown higher than expected substance use (tobacco and alcohol use) in middle-class Hispanic and Black youth and adults. In theory, some of this more than expected risk might be due to the high substance use problem of their social networks. Objectives: To better understand the role of social networks as an explanatory mechanism behind higher than expected substance use among middle-class Hispanic and Black youth, this study tested MDRs of parental educational attainment on substance use involvement of biological relatives in Hispanic and Black middle-class youth. We compared ethnic groups for effects of parental educational attainment on substance use involvement of biological relatives among American youth. Methods: The current longitudinal study used waves 1 and wave 4 data of the Population Assessment of Tobacco and Health-Adolescents (PATH; 2013-2018) study. The sample included 4264 nationally representative American youth who were followed for 4 years. The independent variable was parental educational attainment. The dependent variable was substance use involvement of biological relatives. Age, gender, and marital status of the family were the covariates. Ethnicity was the moderator. Linear regression was used to analyze the data. Results: Parental educational attainment was inversely associated with substance use involvement of biological relatives in the pooled sample $(\mathrm{OR}=1.36,95 \% \mathrm{CI}=1.13-1.63$ for high school graduation and $\mathrm{OR}=0.65,95 \% \mathrm{CI}=0.53-0.80$ for college graduation). Hispanic ethnicity showed statistically significant interactions with parental educational attainment $(\mathrm{OR}=2.26,95 \% \mathrm{CI}=1.49-3.44$ for high school graduation and $\mathrm{OR}=2.98,95 \% \mathrm{CI}=1.80-4.93$ for college graduation), suggesting that the protective effect of parental educational attainment against substance use involvement of biological relatives is smaller for His-
\end{abstract}


panic youth than for non-Hispanic youth. Conclusions: While high parental educational attainment reduces substance use involvement of biological relatives, this protective effect is weaker for Hispanic than non-Hispanic youth. That means, substance use involvement of biological relatives is still high in middle-class Hispanic youth, which increases their risk of substance use. Future research should explore societal and contextual factors that cause MDRs of parental educational attainment on substance use of middle-class Hispanic families.

\section{Keywords}

Population Groups, Ethnicity, Socioeconomic Status, Socioeconomic Position, Education, Smoking, Tobacco Use

\section{Introduction}

In the US, the burden of tobacco use is higher in ethnic minorities compared to the general population [1]. Due to low access, acceptability, and trust in the health care system in general [2] and tobacco cessation programs in particular [1] ethnic minority groups such as Hispanics and Blacks show an increased vulnerability to tobacco-related illnesses such as respiratory disease, cardiovascular conditions, and cancer [3]. As the prevalence of tobacco use is commonly lower in Hispanics and Blacks compared to Whites, the higher burden of tobacco-related diseases in Hispanics and Blacks is a paradoxical area of research [1].

The dominant explanation in the field for ethnic disparities in tobacco-related illnesses is socioeconomic status (SES) inequalities across ethnic minority groups. This is because SES indicators such as educational attainment of self and parents operate as the strongest social determinants of tobacco use [4], and ethnicity and SES closely overlap in the U.S. [5]. As a result, ethnic differences in the burden of tobacco use have been traditionally attributed to the low SES of ethnic minority groups [5]. This has become increasingly important because the health implications of educational attainment are increasing in the lives of Americans [6]. The social gradient of tobacco use as a function of SES, particularly educational attainment, is also becoming more important than before [7] [8].

Recent social epidemiological research, however, has questioned the assumption that ethnic tobacco use disparities are all due to SES inequalities across ethnic groups [9]. A large number of recent findings have shown that middle-class and high SES ethnic minorities remain at "higher than expected" risk of tobacco use [9] [10] [11] [12]. This seems to be especially the case for highly educated Hispanics [13], however, the same pattern is also shown for Native Americans as well [14]. This pattern is known as Marginalization-related Diminished Returns (MDRs), defined as "weaker than expected" health effects of educational attainment and other SES indicators for socially marginalized individuals, compared to the mainstream population [15]. As shown by this literature, highly educated 
Hispanics and Blacks remain at high risk of tobacco use [9]. As similar patterns are shown for Hispanics [9], Blacks, [13] Native Americans [14], and sexual minorities [16], these findings are attributed to marginalization and systemic inequalities that place minority groups at an increased risk of undesired outcomes. This is also supported by an extensive body of research outside tobacco use outcomes, suggesting that MDRs are robust and systemic and hold for several other outcomes [17] [18] [19] [20] [21].

There are many examples of studies documenting higher than expected tobacco use among middle-class Hispanics and Blacks [9] [10] [11] [12]. One study showed higher risk of e-cig use in highly educated Blacks, despite the observation that for Whites, educational attainment was inversely associated with e-cig use [11]. In another study, educational attainment was inversely associated with smoking cigarette for Whites but not Blacks [10]. Another study showed more than expected risk of tobacco use in Hispanics who were employed compared to Whites by documenting that the protective effect of employment on the risk of smoking is smaller for Hispanics than non-Hispanic Whites [9]. All these studies show a high risk of tobacco use in high SES Hispanics and Blacks, compared to high SES non-Hispanic Whites [9] [10] [11] [12]. In a very recent study, second-hand workplace exposure to cigarette smoke was higher in highly educated Hispanics and Blacks, which was attributed to labor market discrimination that gives worse job qualities to Hispanics and Blacks than Whites [22].

High risk of tobacco use in middle-class Hispanics and Blacks is well-established [9] [10] [11] [13], a pattern explained through the MDRs of SES. However, very little is known about the sociological mechanisms of such MDRs. Understanding why MDRs occur could help us understand these counterintuitive findings and act accordingly. Such information is very crucial to suggesting policy solutions that can reduce the existing tobacco disparities in ethnic minorities. Some of the previously studied potential mechanisms of MDRs are economic processes [23] such as lower quality of jobs [24] due to labor market discrimination [15]. Another explanation is a higher psychosocial tax of upward social mobility for ethnic minority people [17] [25] [26]. Another explanation is MDRs due to childhood poverty. Finally, interpersonal discrimination may have a role [27] [28] [29]. Another potential mechanism that has not yet been tested is the role of social networks. SES may have weaker than expected effects on reducing tobacco use in the social networks of ethnic minorities than Whites [30]. As a result of such MDRs, highly educated Hispanics and Blacks might be exposed to social networks that have higher tobacco involvement. To the best of our knowledge, this hypothesis has never been tested before.

\section{Aims}

This longitudinal study used a nationally representative sample to explore ethnic differences in the effects of parental educational attainment on substance use involvement of biological relatives in a national sample of American youth. We 
expected 1) an inverse association between parental educational attainment and substance use involvement of biological relatives overall, however, at the same time we expected 2) a weaker inverse association between parental educational attainment and substance use involvement of biological relatives in Hispanics and Blacks than non-Hispanics and Whites.

\section{Materials and Methods}

\subsection{Design and Settings}

This longitudinal study is a secondary analysis of waves 1 and 4 of the PATHAdolescents data, 2013-2018. PATH is the main longitudinal study of tobacco use in the US. Wave 1 and wave 4 of the data were collected in 2013-2014 and 2017-2018, respectively.

\subsection{Sample and Sampling}

The PATH study's adolescent sample in Wave 1 was the civilian, non-institutionalized, US population 12 - 17 years old in the US. The current analysis was limited to the 5021 adolescents who were never-smokers at baseline and were followed for 4 years and had valid data on their tobacco use at wave 4 . The PATH study used a four-stage stratified area probability sample design to recruit participants. Using stratified sampling, at the $1^{\text {st }}$ stage, 156 primary sampling units (PSUs) were selected. The PATH geographical PSUs were composed of a single county or a group of counties. The $2^{\text {nd }}$ stage was formed from sampled smaller geographical segments in each PSU. The $3^{\text {rd }}$ stage sampled residential addresses. The fourth stage was the selection of one adolescent and adult participant within households. Participants completed a questionnaire using an Audio Computer-Assisted Self-Interview system.

\subsection{Study Variables}

The study variables included adolescent age, gender, ethnicity, parent education, parental marital status, all measured at wave 1, and current cigarette use and involvement of biological relatives in substance use at wave 4 .

\subsubsection{Dependent Variables}

Substance use involvement of biological relatives was measured using the following three items: 1) "Have any of [participants' name]'s close biological or blood relatives used any tobacco products? By this, we mean cigarettes, e-cigarettes or other electronic nicotine products, cigars, pipe, hookah, snus or other types of smokeless tobacco (such as dip, spit or chew), and dissolvable tobacco."; 2) "Have any of [participants' name]'s close biological or blood relatives ever been an alcoholic or problem drinker? By this, we mean a person whose drinking causes problems with their physical or emotional health, family or friends, work or school, or the police."; 3) "Have any of [participants' name]'s close biological or blood relatives ever had problems with drugs? By this, we mean a person whose drug use causes problems with their physical or emotional health, family 
or friends, work or school, or the police." Responses were 0 and 1 . We defined the variable as a binary outcome: 1 = biological relatives involved in substance use, $0=$ biological relatives not involved in substance use.

\subsubsection{Independent Variable}

Parent education. Parent education was measured as a continuous variable ranging from 1 to 5: 1) "less than high school", 2) "GED or high school graduate", 3) "some college (no degree) or associates degree", 4) "Bachelor's degree", and 5) "advanced degree".

\subsubsection{Moderator Variable}

Ethnicity. Adolescent ethnicity was used as moderator variables and was operationalized as two dichotomous variables: Hispanic versus non-Hispanic and Black versus White.

\subsubsection{Confounders}

Age, gender, family structure, and cigarette smoking were the covariates. Age was measured as a dichotomous variable: 1) 12 to 15 years old, 2) 16 to 17 years old. Gender was a dichotomous variable. Parental family structure was a dichotomous variable; $1=$ married, $0=$ otherwise.

Cigarette Smoking. One covariate was cigarette smoking. Ever cigarette smoking was measured using the following question: "Did you ever smoke cigarettes, even a puff?" $(1=$ Yes, $0=$ No $)$.

\subsection{Statistical Analysis}

To adjust the PATH data complex survey design (sample weights), we analyzed our data using SPSS 23.0 (IBM Corporation, Armonk, NY, U.S.). We re-estimated our standard errors using Taylor series linearization. For multivariable modeling, we fitted logistic regression models, with parental educational attainment as a three-level categorical independent variable and Substance use involvement of biological relatives as the binary outcome. We ruled out multicollinearity between our independent variables. We ran models in the pooled sample without and with interaction terms between Hispanic and Black ethnicity and parental educational attainment. Our interaction terms were two multiplicative effects (one for Hispanics and one for Blacks) of ethnicity and higher levels of parental educational attainment. Regression coefficient (B), standard errors (SE), Odds Ratio (OR), 95\% confidence intervals (CI), and $\mathrm{p}$ values were reported.

\subsection{Ethics}

All PATH adolescent participants signed informed assent. Adults in the PATH study signed informed consent. The Institutional Review Board (IRB) of the West at approved the study protocol. Data were collected, restored, and analyzed anonymously. Given this study used fully de-identified publicly available data, this study was found to be exempt from review by the IRB of Charles Drew University of Medicine and Science. 


\section{Results}

\subsection{Descriptive Statistics}

This study included 4264 youth who were followed for 4 years. From this number, most were non-Hispanic (75.3\%) and Whites (80.4\%). Table 1 describes the study variables in the pooled sample.

\subsection{Multivariable Models in the Pooled Sample}

Table 2 presents the results of two logistic regression models in the overall sample with parental educational attainment as the independent variable and substance use involvement of biological relatives as the dependent variable. Model 1showed a negative association between parental educational attainment and substance use involvement of biological relatives $(\mathrm{OR}=1.36,95 \% \mathrm{CI}=1.13$ 1.63 for high school graduation and $\mathrm{OR}=0.65,95 \% \mathrm{CI}=0.53-0.80$ for college graduation), while all covariates were adjusted.

Table 1. Descriptive statistics summary of the overall sample $(n=4264)$.

\begin{tabular}{|c|c|c|}
\hline & $\mathrm{n}$ & $\%$ \\
\hline \multicolumn{3}{|l|}{ Hispanic } \\
\hline No & 3212 & 75.3 \\
\hline Yes & 1052 & 24.7 \\
\hline \multicolumn{3}{|l|}{ Black } \\
\hline No & 3429 & 80.4 \\
\hline Yes & 835 & 19.6 \\
\hline \multicolumn{3}{|l|}{ Age } \\
\hline $12-16$ & 4113 & 96.5 \\
\hline $17-18$ & 151 & 3.5 \\
\hline \multicolumn{3}{|l|}{ Parents married } \\
\hline No & 1544 & 36.2 \\
\hline Yes & 2720 & 63.8 \\
\hline \multicolumn{3}{|l|}{ Parental Education } \\
\hline Less than High School Graduate & 812 & 19.0 \\
\hline High School Graduate & 2136 & 50.1 \\
\hline College Graduate & 1316 & 30.9 \\
\hline \multicolumn{3}{|l|}{ Current smoker (Wave 4) } \\
\hline No & 4023 & 94.4 \\
\hline Yes & 238 & 5.6 \\
\hline \multicolumn{3}{|c|}{ Biological relatives involved in substance Use } \\
\hline No & 1428 & 33.5 \\
\hline Yes & 2836 & 66.5 \\
\hline
\end{tabular}


Table 2. Logistic regression model on substance use involvement in the pooled sample of American youth $(\mathrm{n}=4264)$.

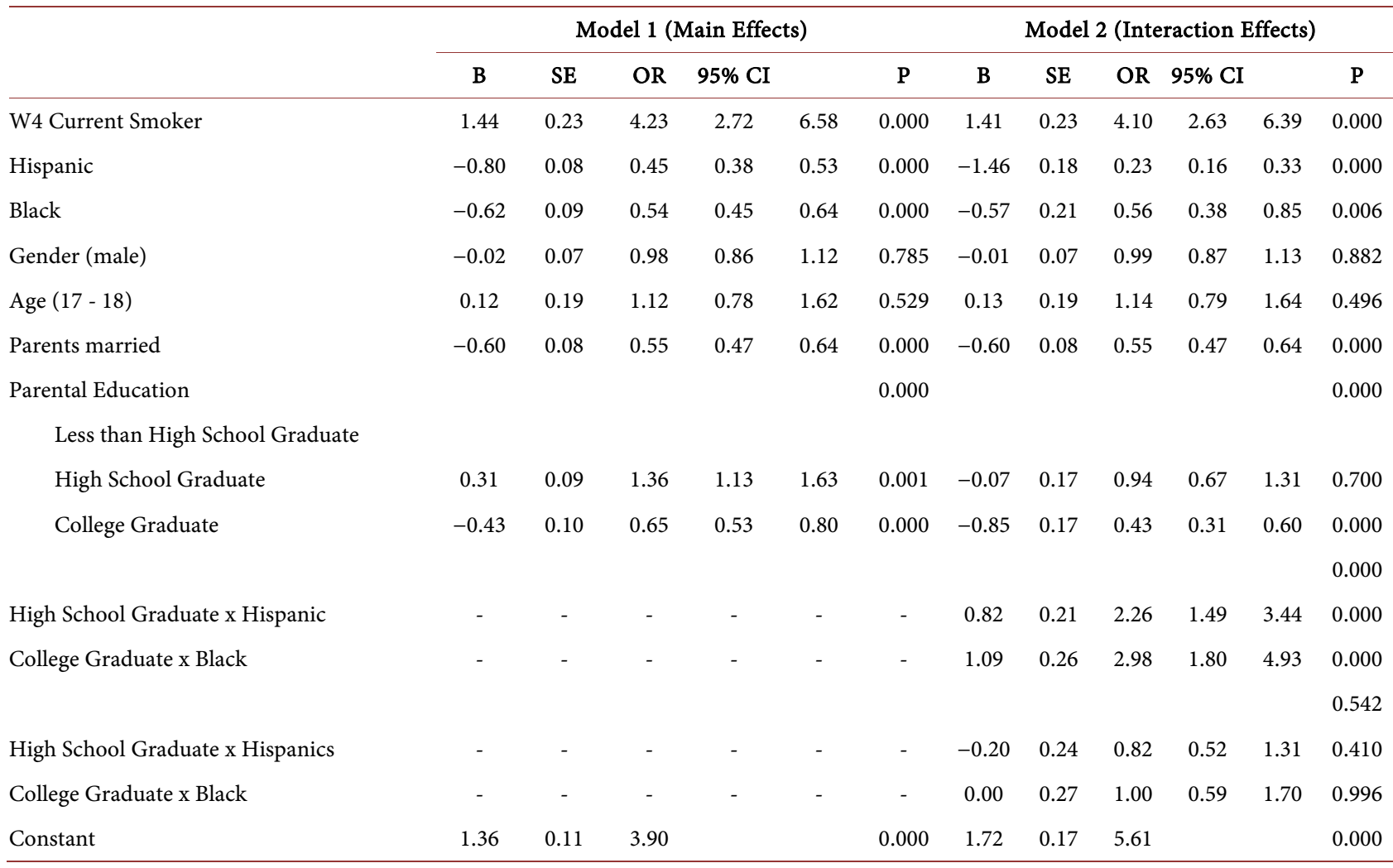

CI: Confidence Interval; b: Regression Coefficient; SE: Standard Error.

Based on Model 2, however, Hispanic ethnicity showed significant interaction with parental educational attainment on substance use involvement of biological relatives, suggesting that the protecting effect of high parental educational attainment against substance use involvement of biological relatives is smaller for Hispanic than non-Hispanic youth $(\mathrm{OR}=2.26,95 \% \mathrm{CI}=1.49-3.44$ for high school graduation and $\mathrm{OR}=2.98,95 \% \mathrm{CI}=1.80-4.93$ for college graduation) (Table 2).

\section{Discussion}

Although high parental educational attainment was associated with lower substance use involvement of biological relatives overall, this effect was smaller for Hispanic than non-Hispanic youth. That means, Hispanic youth with highly educated parents still had biological relatives with substance use involvement. High parental education may better reduce tobacco risk in the social network for non-Hispanic than Hispanic youth.

Based on our observation, one reason middle-class Hispanic youth remain at high risk of tobacco use is that highly educated ethnic minority youth are still exposed to the relatives and family members with high substance use risk. This finding may provide an explanation (from many potential explanations) for why highly educated ethnic minority individuals remain at higher than expected risk 
of smoking, a pattern also known as the diminished returns of parental educational attainment and other SES indicators on reducing tobacco risk for people of color [9] [10] [11] [13].

For several reasons, MDRs of educational attainment on tobacco use among ethnic minorities may be due to inequalities and injustice in the quality of education and schooling. Education quality is a strong determinant of the health effects of education [31]. Thus, when education quality is low, health literacy and tobacco knowledge would remain low, even when the number of years of schooling is high [32]. While education increases anti-tobacco and lowers pro-tobacco attitudes [32], education's effect on these cognitive factors is relative to the quality of education received. It is only a good quality education that has such effect, and due to the racism and segregation, people of color and ethnic minorities are less likely to receive such education [33]. As a result, overall, the risk of tobacco use stays high at predominantly ethnic minority schools [31]. This hypothesis, which should be tested in future research, is supported by the observation that ethnic minority people who smoke cigarettes have a disproportionately low perception of their risk [34]. Such a gap between real and perceived risk may explain why education has smaller effects on reducing tobacco risk for ethnic minority people across education levels [9].

On top of the poorer education quality, ethnic minorities are also targets of predatory marketing practices of the tobacco industry that specifically targets communities of color [35], which may influence their attitude about tobacco. In such a view, the tobacco industry may manipulate ethnic groups' knowledge and attitudes about tobacco products [36]. Thus, we argue that high substance use involvement of relatives may be a mechanism that causes a lower protective effect of educational attainment on tobacco use of ethnic minorities [9]. In the presence of MDRs of educational attainment [9], however, we may observe disproportionately high substance use involvement in the social networks of highly educated Hispanic individuals relative to non-Hispanics. This may be because educational attainment has smaller effects on improving the life conditions of ethnic minorities than Whites. As a result, interventions for high SES Hispanic individuals remain suboptimal in the absence of interventions or addressing the substance use of their social network, which may affect their tobacco use [9].

Knowing that SES is not merely mediating but also moderating ethnic tobacco disparities has major implications for policy setting particularly for allocation of resources in order to eliminate such inequalities. If SES inequalities were responsible for ethnic disparities (not supported here), then elimination of ethnic inequalities would be dependent on elimination of economic inequalities across groups. However, the story is more complicated than that. Tobacco disparities are not all due to SES differences. Some of the tobacco disparities in ethnic minorities are because of a voltage drop of education in such groups. This voltage drop requires policies and interventions other than equalizing SES across groups. Non-economic policies and those that focus on structural risk factors of tobacco use in people of color (e.g. tobacco marketing policies) seem to be also required. 
MDRs are not limited to tobacco use. Similar MDRs (smaller effects of educational attainment) are reported for a wide range of health outcomes such as depression, obesity, chronic disease, and mortality, all of which are greater for high SES Hispanics and Blacks than Whites [9] [37] [38].

This highlights the need to understand the mechanisms by which ethnic tobacco use disparities emerge in high SES people. MDRs propose environmental, societal, social, structural, and behavioral processes that reduce the health gains of educational attainment, resulting in less reduction of the risk of tobacco use for highly educated ethnic minorities. Thus, MDRs introduce a paradigm shift to study tobacco use: it reconceptualizes the combined effects of race and SES from a mediated path to a moderated one.

As a result of the smaller effects of parental and own educational attainment for ethnic minority groups [37], the relative ethnic gap in tobacco use may widen, rather than narrow, at higher levels of education levels [9]. This is a threat to what the U.S. has done so far to reduce tobacco risk in the U.S. [8]. Previous research has also shown that tobacco use has become more concentrated in low educated individuals [8].

Not all the ethnic disparities in tobacco risk are due to individuals' poor choices. As this study shows, structural factors may have a role in shaping higher than expected risk of tobacco use in ethnic minority youth. This paper suggests that some of this additional risk is due to social forces that are beyond their control. While this study focused on the level of risk of families and relatives, other studies have suggested that predatory marketing of the tobacco industry and increasing minorities' exposure and access to tobacco may also have a role [39] [40] [41] [42].

Research may also explore the role of structural factors such as residential segregation, concentration of poverty, and density of tobacco retail stores that may impact youth risk of substance use. We found that more than expected risk of substance use in biological relatives may explain why tobacco use is more than expected in middle-class ethnic minority youth. We still need to study the best strategies to reduce social and environmental risk factors of tobacco use for ethnic minorities including those that are due to the MDRs (diminished returns) of SES.

\subsection{Implications}

This study offers new policy and public health implications. The results suggest that addressing substance use risk of the social network may be needed to enhance the efficacy of preventive interventions to reduce tobacco use in middle-class Hispanic youth. Focusing on substance use involvement at the family level, rather than focusing on the tobacco use of the individual may better contribute to the elimination of ethnic disparities in tobacco use, particularly those due to MDRs of parental educational attainment in middle-class ethnic minorities. The result reported here helps us understand why Hispanic youth who are 
highly educated are still susceptible to using tobacco products [43]. The results may thus offer a solution to reduce such vulnerability. We argue that tobacco prevention strategies that focus on middle-class ethnic minorities may benefit from campaigns that educate the whole community, family, and relatives (across age groups) which may reduce some of the tobacco-related disparities in middle and high SES Hispanics.

\subsection{Limitations}

This study had some methodological limitations. We had unbalanced sample size across ethnic groups. To avoid differential statistical power by ethnicity, we did not run any regression models specific to our ethnic groups. To reduce bias due to differential power across ethnic groups, we ran models with interaction terms in the pooled sample. We only focused on the MDRs of parental educational attainment and other SES indicators such as wealth and poverty status were left out. Future research may explore MDRs of other SES such as neighborhood SES.

\subsection{Conclusion}

Ethnic minority youth experience a weaker protective effect of parental educational attainment on substance use involvement of their biological relatives (i.e. social network). While, in general, high parental educational attainment means less substance use involvement at the family/relatives for American youth, some social processes diminish this effect for Hispanics compared to non-Hispanic Whites. Thus, middle-class Hispanic youth are exposed to a high risk of substance use in their social network. More research is needed on other social and structural factors that may explain high risk of tobacco use in middle-class Hispanic youth and adults.

\section{Conflicts of Interest}

The authors declare no conflicts of interest regarding the publication of this paper.

\section{Funding}

The research reported in this publication was supported by the National Cancer Institute, National Institutes of Health (NIH) and FDA Center for Tobacco Products (CTP) under Award Number U54CA229974. The content is solely the responsibility of the authors and does not necessarily represent the official views of the NIH or the Food and Drug Administration.

\section{Authors' Contributions}

S.A. conceptualized the study, analyzed the data, prepared the first draft of the paper, and revised the paper. Other authors contributed to the draft. All authors approved the final draft. 


\section{References}

[1] Trinidad, D.R., Perez-Stable, E.J., White, M.M., Emery, S.L. and Messer, K. (2011) A Nationwide Analysis of US Racial/Ethnic Disparities in Smoking Behaviors, Smoking Cessation, and Cessation-Related Factors. American Journal of Public Health, 101, 699-706. https://doi.org/10.2105/AJPH.2010.191668

[2] Smedley, B.D., Stith, A.Y. and Nelson, A.R., Eds. (2003) Unequal Treatment: Confronting Racial and Ethnic Disparities in Health Care. Washington DC.

[3] Greaves, L. and Hemsing, N. (2009) Women and Tobacco Control Policies: Social-Structural and Psychosocial Contributions to Vulnerability to Tobacco Use and Exposure. Drug and Alcohol Dependence, 104, S121-S130.

https://doi.org/10.1016/j.drugalcdep.2009.05.001

[4] Zhang, X., Martinez-Donate, A.P. and Jones, N.R. (2013) Educational Disparities in Home Smoking Bans among Households with Underage Children in the United States: Can Tobacco Control Policies Help to Narrow the Gap? Nicotine \& Tobacco Research, 15, 1978-1987. https://doi.org/10.1093/ntr/ntt090

[5] Wallace Jr., J.M., Vaughn, M.G., Bachman, J.G., O’Malley, P.M., Johnston, L.D. and Schulenberg, J.E. (2009) Race/Ethnicity, Socioeconomic Factors, and Smoking among Early Adolescent Girls in the United States. Drug and Alcohol Dependence, 104, S42-S49. https://doi.org/10.1016/j.drugalcdep.2009.06.007

[6] Montez, J.K. and Zajacova, A. (2013) Explaining the Widening Education Gap in Mortality among U.S. White Women. Journal of Health and Social Behavior, 54, 166-182. https://doi.org/10.1177/0022146513481230

[7] Rock, V.J., Davis, S.P., Thorne, S.L., Asman, K.J. and Caraballo, R.S. (2010) Menthol Cigarette Use among Racial and Ethnic Groups in the United States, 2004-2008. Nicotine \& Tobacco Research, 12, S117-S124. https://doi.org/10.1093/ntr/ntq204

[8] Drope, J., Liber, A.C., Cahn, Z., Stoklosa, M., Kennedy, R., Douglas, C.E., Henson, R. and Drope, J. (2018) Who's Still Smoking? Disparities in Adult Cigarette Smoking Prevalence in the United States. CA: A Cancer Journal for Clinicians, 68, 106-115. https://doi.org/10.3322/caac.21444

[9] Shervin, A. and Ritesh, M. (2019) Diminished Return of Employment on Ever Smoking among Hispanic Whites in Los Angeles. Health Equity, 3, 138-144. https://doi.org/10.1089/heq.2018.0070

[10] Assari, S. and Mistry, R. (2018) Educational Attainment and Smoking Status in a National Sample of American Adults; Evidence for the Blacks' Diminished Return. International Journal of Environmental Research and Public Health, 15, 763. https://doi.org/10.3390/ijerph15040763

[11] Assari, S., Mistry, R. and Bazargan, M. (2020) Race, Educational Attainment, and E-Cigarette Use. Journal of Medical Research and Innovation, 4, e000185. https://doi.org/10.32892/jmri.185

[12] Assari, S., Caldwell, C.H. and Bazargan, M. (2020) Association between Parental Educational Attainment and Youth Outcomes and Role of Race/Ethnicity. JAMA Network Open, 2, e1916018. https://doi.org/10.1001/jamanetworkopen.2019.16018

[13] Assari, S., Farokhnia, M. and Mistry, R. (2019) Education Attainment and Alcohol Binge Drinking: Diminished Returns of Hispanics in Los Angeles. Behavioral Sciences (Basel), 9, 9. https://doi.org/10.3390/bs9010009

[14] Assari, S. and Bazargan, M. (2019) Protective Effects of Educational Attainment Against Cigarette Smoking; Diminished Returns of American Indians and Alaska Natives in the National Health Interview Survey. International Journal of Travel Medicine and Global Health, 7, 105-110. https://doi.org/10.15171/ijtmgh.2019.22 
[15] Assari, S. (2018) Blacks' Diminished Return of Education Attainment on Subjective Health; Mediating Effect of Income. Brain Sciences, 8, 176. https://doi.org/10.3390/brainsci8090176

[16] Assari, S. and Bazargan, M. (2019) Education Level and Cigarette Smoking: Diminished Returns of Lesbian, Gay and Bisexual Individuals. Behavioral Sciences (Basel), 9, 103. https://doi.org/10.3390/bs9100103

[17] Assari, S. (2018) Race, Intergenerational Social Mobility and Stressful Life Events. Behavioral Sciences (Basel), 8, E86. https://doi.org/10.3390/bs8100086

[18] Assari, S. (2018) Socioeconomic Status and Self-Rated Oral Health; Diminished Return among Hispanic Whites. Dentistry Journal(Basel), 6, 11. https://doi.org/10.3390/dj6020011

[19] Assari, S. (2018) The Benefits of Higher Income in Protecting against Chronic Medical Conditions Are Smaller for African Americans than Whites. Healthcare (Basel), 6, 2. https://doi.org/10.3390/healthcare6010002

[20] Assari, S. (2018) Life Expectancy Gain Due to Employment Status Depends on Race, Gender, Education, and Their Intersections. Journal of Racial and Ethnic Health Disparities, 5, 375-386. https://doi.org/10.1007/s40615-017-0381-x

[21] Assari, S. (2019) Socioeconomic Determinants of Systolic Blood Pressure; Minorities' Diminished Returns. Journal of Health Economics and Development, 1, 1-11.

[22] Assari, S. and Bazargan, M. (2019) Unequal Effects of Educational Attainment on Workplace Exposure to Second-Hand Smoke by Race and Ethnicity; Minorities' Diminished Returns in the National Health Interview Survey (NHIS). Journal of Medical Research and Innovation, 3, e000179. https://doi.org/10.32892/jmri.179

[23] Assari, S. (2018) Parental Education Better Helps White than Black Families Escape Poverty: National Survey of Children's Health. Economies, 6, 30. https://doi.org/10.3390/economies6020030

[24] Assari, S. and Bazargan, M. (2019) Unequal Associations between Educational Attainment and Occupational Stress across Racial and Ethnic Groups. International Journal of Environmental Research and Public Health, 16, 3539. https://doi.org/10.3390/ijerph16193539

[25] Assari, S. (2018) Parental Education Attainment and Educational Upward Mobility; Role of Race and Gender. Behavioral Sciences (Basel), 8, 107. https://doi.org/10.3390/bs8110107

[26] Assari S. (2019) Parental Educational Attainment and Academic Performance of American College Students; Blacks' Diminished Returns. Journal of Health Economics and Development, 1, 21-31.

[27] Assari, S. and Caldwell, C.H. (2018) Social Determinants of Perceived Discrimination among Black Youth: Intersection of Ethnicity and Gender. Children (Basel), 5, 24. https://doi.org/10.3390/children5020024

[28] Assari, S., Gibbons, F.X. and Simons, R.L. (2018) Perceived Discrimination among Black Youth: An 18-Year Longitudinal Study. Behavioral Sciences (Basel), 8, 44. https://doi.org/10.3390/bs8050044

[29] Assari, S. and Moghani Lankarani, M. (2018) Workplace Racial Composition Explains High Perceived Discrimination of High Socioeconomic Status African American Men. Brain Sciences, 8, 139. https://doi.org/10.3390/brainsci8080139

[30] Simon, P., Camenga, D.R., Morean, M.E., Kong, G., Bold, K.W., Cavallo, D.A. and Krishnan-Sarin, S. (2018) Socioeconomic Status and Adolescent e-Cigarette Use: The Mediating Role of e-Cigarette Advertisement Exposure. Preventive Medicine, 112, 193-198. https://doi.org/10.1016/j.ypmed.2018.04.019 
[31] Sisco, S., Gross, A.L., Shih, R.A., Sachs, B.C., Glymour, M.M., Bangen, K.J., Benitez, A., Skinner, J., Schneider, B.C. and Manly, J.J. (2015) The Role of Early-Life Educational Quality and Literacy in Explaining Racial Disparities in Cognition in Late Life. Journals of Gerontology: Series B, Gerontological Society of America, 70, 557-567. https://doi.org/10.1093/geronb/gbt133

[32] An, D.T.M., Minh, H.V., Huong, L.T., Giang, K.B., Xuan, L.T.T., Hai, P.T., Nga, P.Q. and Hsia, J. (2013) Knowledge of the Health Consequences of Tobacco Smoking: A Cross-Sectional Survey of Vietnamese Adults. Global Health Action, 6, 1-9. https://doi.org/10.3402/gha.v6i0.18707

[33] Assari, S. and Lankarani, M.M. (2016) Race and Urbanity Alter the Protective Effect of Education but Not Income on Mortality. Frontiers in Public Health, 4, 100. https://doi.org/10.3389/fpubh.2016.00100

[34] Assari, S., Khoshpouri, P. and Chalian, H. (2019) Combined Effects of Race and Socioeconomic Status on Cancer Beliefs, Cognitions, and Emotions. Healthcare (Basel), 7, 17. https://doi.org/10.3390/healthcare7010017

[35] Lewis, M.J., Delnevo, C.D. and Slade, J. (2004) Tobacco Industry Direct Mail Marketing and Participation by New Jersey Adults. American Journal of Public Health, 94, 257-259. https://doi.org/10.2105/AJPH.94.2.257

[36] Soneji, S., Knutzen, K.E., Tan, A.S.L., Moran, M.B., Yang, J., Sargent, J. and Choi, K. (2019) Online Tobacco Marketing among US Adolescent Sexual, Gender, Racial, and Ethnic Minorities. Addictive Behaviors, 95, 189-196. https://doi.org/10.1016/j.addbeh.2019.03.015

[37] Assari, S. (2017) Unequal Gain of Equal Resources across Racial Groups. International Journal of Health Policy and Management, 7, 1-9. https://doi.org/10.15171/ijhpm.2017.90

[38] Assari, S. (2018) Health Disparities Due to Diminished Return among Black Americans: Public Policy Solutions. Social Issues and Policy Review, 12, 112-145. https://doi.org/10.1111/sipr.12042

[39] Agaku, I.T. and Ayo-Yusuf, O.A. (2014) The Effect of Exposure to Pro-Tobacco Advertising on Experimentation with Emerging Tobacco Products Among U.S. Adolescents. Health Education \& Behavior, 41, 275-280. https://doi.org/10.1177/1090198113511817

[40] Kim, A.E., Loomis, B.R., Busey, A.H., Farrelly, M.C., Willett, J.G. and Juster, H.R. (2013) Influence of Retail Cigarette Advertising, Price Promotions, and Retailer Compliance on Youth Smoking-Related Attitudes and Behaviors. Journal of Public Health Management and Practice, 19, E1-E9. https://doi.org/10.1097/PHH.0b013e3182980c47

[41] Pierce, J.P., Sargent, J.D., White, M.M., Borek, N., Portnoy, D.B., Green, V.R., Kaufman, A.R., Stanton, C.A., Bansal-Travers, M., Strong, D.R., et al. (2017) Receptivity to Tobacco Advertising and Susceptibility to Tobacco Products. Pediatrics, 139, e20163353. https://doi.org/10.1542/peds.2016-3353

[42] Unger, J.B., Cruz, T.B., Schuster, D., Flora, J.A. and Johnson, C.A. (2001) Measuring Exposure to Pro- and Anti-Tobacco Marketing among Adolescents: Intercorrelations among Measures and Associations with Smoking Status. Journal of Health Communication, 6, 11-29. https://doi.org/10.1080/10810730150501387

[43] The Food and Drug Administration (FDA) (2019) Research Priorities. https://www.fda.gov/tobacco-products/research/research-priorities 